\title{
La Convicción, Un Arma Imprescindible En La Protección De Niñas Y Niños Víctimas ${ }^{1}$
}

Lic. Ubelexis Rondón Cantero ${ }^{2}$

\section{RESUMEN}

En este artículo se valora la convicción como imprescindible a las victimas específicas de niños y niñas, observando cómo esto es tratado en el Derecho Penal. Resalta también para la Fiscalía y también para Cuba como un país que tiene como prioritario este punto. Valora la defensa a los infantes víctimas como una tarea de todos, además el deber de tener como prioridad. Aborda el concepto di victima como cualquier persona que haya sufrido daño físico, psíquico, financiero o de sus derechos como persona a consecuencia de una acción u omisión regida en Ley como delito.

Palabras clave: Convicción. Victimas. Protección de los niños y niñas.

\section{INTRODUCCIÓN}

En Cuba la protección a la niñez y la juventud tiene carácter prioritario, establecida desde los postulados constitucionales y desdobladas en no pocas normativas incluida la relativa al Derecho Penal. Resulta especialmente interesante la tutela penológica que brinda el Estado para aquellos que vulneran los derechos proclamados por los

1 Data de recebimento: 18/05/2017. Data de aceite: 18/06/2018.

2 Fiscal. Fiscalía Provincial Cienfuegos. E-mail: relaciones@fgr.gob.cu 
organismos internacionales y acogidos por varios de nuestros cuerpos legales. No obstante la Justicia se enfrenta a la delicada tarea de emitir un juicio de credibilidad respecto del testimonio de una víctima, muchas veces constituida como la prueba principal.

Para los operadores del Derecho ello implica realizar un esfuerzo en dependencia de la posición que le corresponda en el proceso para alcanzar la convicción y convencimiento objetivo del hecho investigado o juzgado. Para los jueces, el desafío de emitir un juicio de valor debiendo pronunciarse y explicitar circunstanciadamente cada uno de los supuestos fácticos y argumentaciones jurídicas esgrimidos en estrados por las partes resulta una alta responsabilidad a la que el fiscal tiene que contribuir de manera efectiva.

Según la UNICEF (Abril 2002) se calcula que cada año un millón de menores de edad, la mayoría niñas, están en las redes del comercio sexual. A los niños más vulnerables se les traslada dentro y fuera de las fronteras para someterlos a la prostitución, la pornografía y a formas intolerables de trabajo infantil. En Cuba la realidad es diferente.

Con independencia de los esfuerzos, en los últimos tiempos, se aprecia una incidencia nada despreciable de la comisión de delitos de Abusos Lascivos, Corrupción de Menores y Otros Actos Contrarios al Normal Desarrollo del Menor. Esto unido a la constante evaluación de estos temas para lograr un perfeccionamiento en las investigaciones nos ha motivado al análisis del contexto actual y nos llevan a emitir consideraciones al respecto.

\section{DESARROLLO}

El niño víctima de la violencia delictiva forma parte de la problemática del delito y de la violencia en general, así como es parte de la Victimología. No obstante es ineludible que dentro de estos sectores de la población y cuando se trata de niños, se hiere más la sensibilidad humana de todos los ciudadanos. Aún así se estudia 
y se conoce más profundamente sobre los victimarios del infante que sobre el propio niño víctima y en ocasiones esto forma parte de un acicate más para hacerlos vulnerables dentro de un determinado proceso.

Defender a los infantes víctimas es una tarea obligada de todos, por lo que no es soberanía exclusiva del Estado; el Doctor Luis Rodríguez Manzanera en su ensayo "Victimología y Derechos Humanos" lo resumió de la siguiente manera: "Sentimos que la atención de los especialistas se ha centrado en los derechos de los delincuentes, olvidando en mucho los de las víctimas" (1996:10).

Entre los actos que la población concibe como los más siniestros, está el de los delitos sexuales, cuyo origen se explica con raíces milenarias y que constituye un fenómeno que no es privativo de algún lugar del mundo, convirtiéndose en un tema de prioridad para análisis e investigación criminológica, y si estos delitos sexuales se realizan contra menores son mucho más repudiados y provocan incalculables consecuencias en el futuro adulto. En Cuba también se valora de forma especial la responsabilidad de la familia en su educación, formación y cuidado.

Para la sistemática de la normativa patria es considerado menor al sujeto con edad de 15 años o menos, es decir, inferior a la mayoría de edad penal de 16 años. Lo anterior está ligado evidentemente a patrones relacionados con el desarrollo físico, intelectual y emocional que requieren edades específicas apropiadas para definir al niño.

Por su parte la víctima podemos considerarla desde el punto de vista gramatical como el ser destinado al sacrificio personal que se expone a un grave riesgo en obsequio de otra, padecer por culpa ajena o por causa fortuita (Diccionario ARISTOS, 1985:16). Para la Victimología, víctima es todo aquel sujeto que sufre por la comisión de una conducta antisocial aunque no sea detentador del derecho vulnerado. El más universal y aceptado de todos los conceptos de víctimas que conocemos, y que es sustentado por la Declaración 
de la Organización de las Naciones Unidas (año 1985-1989), es:

\begin{abstract}
Se entenderá por víctima las personas que individual o colectivamente hayan recibido daños, inclusive lesiones físicas o mentales, sufrimiento emocional, pérdidas financieras o menoscabo sustancial de sus derechos fundamentales, como consecuencia de acciones y omisiones que violan la legislación penal vigente en los estados miembros, incluido lo que prescribe el abuso de poder" (Instrumentos Jurídicos Para la Infancia, 1996: 23).
\end{abstract}

Podrá considerarse víctima a una persona, independientemente a que se identifique, aprehenda en juicio o condene al perpetrador e independientemente de la relación familiar entre el perpetrador y la víctima.

En la expresión Víctima se incluye, además, en su caso, a las familias o personas a su cargo que tengan relación inmediata con la víctima directa y a las personas que hayan sufrido daños al intervenir para asistir a la víctima en peligro o para prevenir la victimización.

Así, en materia penal es considerada víctima a toda persona que ha sufrido daño físico, psíquico, financiero o de sus derechos como persona a consecuencia de una acción u omisión regida en Ley como delito. Bajo ese concepto debemos considerar a la víctima en su rol con el derecho penal, tanto sustantivo como adjetivo.

Las formas clínicas del maltrato son muy variadas, existiendo el maltrato físico, el cual tiene múltiples formas de presentación que incluyen: la golpiza, quemadura, heridas por armas blancas, sofocación, abuso sexual cada una con sus rasgos distintivos. Es importante, sobre todo, considerar que una conducta es abusiva cuando es vivida y sentida de este modo por el niño o la niña, cuando miran, tocan, o cuando son mirados o tocados de un modo que les daña.

Durante los últimos años ha existido una significativa ocurrencia de ellos que tienen como blanco niñas y niños, lo que obliga a un análisis de todo lo relacionado con ello, tanto desde el punto de vista criminológico, como preventivo o investigativo. Para la Fiscalía la 
protección de la infancia constituye una prioridad.

Para quienes investigan la comisión de actos delictivos y entre ellos aquellos en los que resultan víctima los infantes, la indagación implica realizar un esfuerzo de convicción y convencimiento antes los tribunales. Por su parte, a los magistrados corresponde el desafío de emitir un juicio de valor debiendo pronunciarse y explicitar circunstanciadamente cada uno de los supuestos fácticos y argumentaciones jurídicas esgrimidos en estrados por las partes. Hoy se fortalecen los esfuerzos por lograr resultados más locuaces con intervenciones mínimas, sin embargo no siempre se reciben o interpretan adecuadamente, en nuestro criterio.

La investigación y tratamiento penal a eventos en los que resultan victimizados niños suelen ser especialmente complejos, la posibilidad de los menores de describir el propio hecho en el que fueron victimizados es a veces cuestionada, a la vez que en muchos casos, paradójicamente, no se cuenta sino con su testimonio como pieza fundamental para intentar demostrar su ocurrencia, como sucede con frecuencia en los casos de los delitos sexuales.

Para los jueces resulta que el juicio de valor incide directamente en la evaluación que realizan respecto de la víctima y su contexto e historia personal: ¿dice la verdad un menor cuando relata haber sido víctima de tocaciones?, ¿pudo haber sido objeto de influencias para denunciar?, ¿porqué denunció ahora y no antes?, ¿se observa un menor afectado psicológicamente por los hechos que resalta?, etc. Las respuestas no son sencillas, no basta el análisis racional, la pasión o el sentido común si uno de ellos excluye al otro, pero se requiere para ello de sapiencia, confianza y de un adecuado argumento investigativo. Corresponde al fiscal convertirse en el sostén que requiere el niño para ser escuchado y protegido ante un hecho vivido con toda certeza.

Desde finales del siglo pasado autores que dedicaron su obra al estudio de la Psiquiatría y la Psicología Judicial incluyeron en 
los mismos aspectos relativos a la peritación de la víctima. En los últimos años toma auge en el estudio de las causas y condiciones que determinan el delito como fenómeno social, el análisis de los factores victimales. En este contexto hay un punto en que se acentúa aún más esta semiexclusión bibliográfica, el referido al testimonio de los niños víctimas de delitos (Evaluación Pericial Psicológica de Credibilidad de Testimonio, 2008).

El testimonio no es más que la huella de un hecho que aunque subjetivamente, puede resultar útil para establecer las características esenciales del fenómeno, en este caso hecho delictivo, que lo determinó y que a la vez se refleja en él. La experiencia indica que la prueba pericial que analiza el testimonio de la víctima es un aporte fundamental a la decisión del juez en la medida que provee elementos de convicción que pueden servir de base al pronunciamiento de una sentencia, especialmente en cualquier delito que trascurra con pocos elementos criminalísticos de otro carácter.

Tal es el caso de los delitos sexuales que se producen contra menores, los cuales muchas veces no van a dejar otra huella, ni otra oportunidad de abordaje criminalístico, que el recuerdo del niño, aún cuando las sinuosidades psicológicas propias de las edades tempranas de la vida hagan difícil su interpretación. Incluso en determinados casos donde existen algunos elementos objetivos o testificales que demuestran la ocurrencia del delito contra el menor, la exploración de su testimonio permitirá complementar a estos en aspectos tales como, el modus operandi, lugar, circunstancias, o presiones psicológicas.

La importancia del testimonio de la víctima de abuso sexual, por mencionar aquellos de mayor incidencia en el estudio criminológico radica que es la única fuente para poder obtener algunas variables de interés del grupo delictivo, además de ser una de las vías para establecer si estamos en presencia de una víctima real o falsa.

Las principales deficiencias investigativas, de acuerdo a las valo- 
raciones realizadas por especialistas en distintos escenarios, recaen hoy en lo siguiente:

Falta de profundidad, multilateralidad y objetividad en la investigación de estos ilícitos, ocasionada por la falta de preparación de los actuantes para enfrentar estos hechos, lo que motiva:

1. Demora en radicar la denuncia por el desconocimiento sobre la calificación legal del hecho, con trascendencia a la competencia.

2. Declaración del denunciante omisa y poco profunda, lo que impide la realización correcta y oportuna del llamado "primer ataque".

3. No se practican diligencias y acciones de instrucción necesarias para la probanza del hecho (ILH, declaración de testigos de presenciales y de referencia, experimentos de instrucción).

4. En ocasiones no se realiza el reconocimiento médico legal del menor.

5. Generalmente se omite el examen físico del acusado.

6. Investigaciones complementarias formales y poco profundas.

7. No se explotan las posibilidades que ofrece la criminalística (peritajes de odorología, biológicos, grafológicos, etcétera)

8. No se acompaña evaluación del centro estudiantil sobre el explorado (cuando se trata de niños en edad escolar y adolescentes) sobre los cambios de conducta y actitud, posibles variaciones en los resultados académicos, etcétera)

9. Dilación innecesaria en la tramitación del proceso, especialmente en la realización de la exploración del menor.

10. Confusión entre el examen exploratorio del menor y la validación del testimonio.

11. Falta de preparación previa para la realización de la exploración del menor.

En cuanto a la investigación debemos añadir también que pueden obstaculizar la obtención del testimonio de un infante la presencia del representante legal en el momento que se toman las declaraciones, ya que puede producir una distorsión descriptiva, cuando el menor 
trate de evitar la comunicación de situaciones que pueden acarrearle sensación de culpa o temor al castigo, lo que desde su posición puede subjetivamente equipararse a situaciones previstas para los casos en los que el declarante es un adulto.

Con respecto a la declaración de la víctima se debe coordinar el trabajo con la policía, de tal manera, que si ésta efectúa la denuncia, en el parte policial se consignen las circunstancias del hecho, pero que no proceda este órgano a tomar una declaración adicional a la víctima, reservándola para que la diligencia se efectúe en presencia del fiscal, aunque no sea un requisito sine qua non, o ser entrevistado exclusivamente por los especialistas quienes brindarán su informe o su criterio de utilidad o no para el Proceso Penal.

Por su parte son varias las posibles tareas periciales a cumplir en la víctima, con las diligencias periciales y en menor o mayor grado, resulta imprescindible el enfoque interdisciplinario, ese al que se encaminan los esfuerzos y así evitar reiterados exámenes que agudicen los efectos del acto. En este estilo de trabajo, las tareas periciales propiamente psicopatológicas a cumplir en la víctima serán las siguientes:

1. Estado mental de la víctima en el momento del hecho delictivo: De especial interés en determinados delitos, los cuales incluso pueden ser tipificados todo en base a ese elemento. Resulta de especial importancia en delitos como la Violación, Pederastia con Violencia y Abusos Lascivos.

2. Estado mental de la víctima con posterioridad al hecho delictivo. A determinar en delitos en los que se prevé la posibilidad de - secuelas psíquicas, como delito de lesiones y la violación, o - enfermedad grave derivadas del hecho.

3. Validación del testimonio en víctimas de delitos. Cada una de estas tareas está determinada por requerimientos judiciales específicos dentro del proceso penal concreto. Toda demanda de pericia proveniente del sistema se origina mediante una solicitud formal al 
perito para que, en virtud de sus especiales conocimientos, pueda intentar aclarar o aportar sobre algún punto materia de controversia o litigio.

¿Qué es la Validación del testimonio en víctimas de delitos?

- Procedimiento pericial médico-legal.

- No hay que realizarla en todos los casos, solo en los que resulte dudoso algún aspecto de la exploración.

- No se hace inmediatamente después de la denuncia, pero sí lo más cercano posible a la exploración.

- Su objetivo es analizar el contenido del testimonio infantil, para lo cual pueden emplearse maniobras de comprobación y explicar aparentes irregularidades.

- Califica lo que el menor describe, pero nunca si es veraz o no, tan solo confiable o útil para el proceso.

Empero los informes sobre validación de testimonios de los menores víctimas pueden resultar solicitudes omisas, donde no se concreta lo que se quiere obtener del peritaje o dejar de comprender elementos esenciales, tampoco aportar para este momento la exploración que se le tomó con anterioridad al menor, sino una síntesis de los hechos, con un valor incalculable, es una herramienta directa con que cuenta el perito a la hora de realizar su trabajo. Así mismo en la síntesis de los hechos se requiere mencionar el lugar donde fueron ejecutados, la fecha, edad del menor y el acusado, y relaciones que unen a víctimas y victimarios, aspectos que determinan la calidad del informe y dan muestra de la confianza del actuante en resultado al que aspira con su búsqueda.

En el caso de solicitarse el análisis pericial o validación del testimonio de niñas, niños o adolescentes de menos de 16 años de edad, será también imprescindible la remisión escrita del contenido de su exploración y los puntos de duda que explican la solicitud de esa pericia (Ídem). No debemos olvidar que, el origen de esta consulta que se hace desde el mundo jurídico al psicológico, se encuentra 
asentada en la necesidad tanto del fiscal como del juez, de valorar aspectos que no son estrictamente jurídicos.

Debemos valorar en su justa medida que por la naturaleza y principios del proceso judicial, el informe y sus conclusiones no son vinculantes a la decisión que va a tomar el tribunal colegiado, que se erige en perito superior. La fuerza probatoria será estimada por los jueces teniendo en cuenta la competencia de los peritos, la unidad o disconformidad de sus opiniones, los principios científicos o técnicos en que se fundan, y la concordancia de su aplicación con las reglas de su sana crítica.

El informe pericial psicológico tiene que estar debidamente fundamentado y carecerá de eficacia probatoria si no fuese claro y sus explicaciones aparecieran contradictorias o deficientes. En este punto podemos plantear que es necesario que un informe pericial se baste a sí mismo, es decir, contenga en su cuerpo todos los elementos de juicio suficientes para que sus conclusiones sean el resultado natural y esperado de su desarrollo (Ídem).

La evaluación pericial psicológica de la credibilidad del testimonio, y más específicamente el interés judicial por determinar la credibilidad de una declaración en el marco de una investigación criminal, se remonta a comienzos de siglo pasado. Un claro ejemplo de ello es que, de acuerdo a Steller y Köehnken, "en los años 30 aparecieron por primera vez en la literatura alemana psicológica y judicial los criterios de realidad" (Ídem).

Cuándo debe solicitarse la Validación.

- Cuando el Instructor o Fiscal dudan de la confiabilidad del testimonio.

- Cuando existen contradicciones en el propio testimonio del menor.

- Cuando hay indicios de inducciones en el mismo.

- Cuando no es lógico o coherente.

- Cuando aparecen elementos fantásticos. 
- Cuando el afecto es contrario a lo que narra el menor.

- Cuando utiliza un lenguaje propio del adulto y reacomodos en su narración.

- Cuando no es espontáneo y fluido.

- A veces cuando es el único elemento que existe para fundamentar el delito.

Admitir que el testimonio del niño carece totalmente de valor, dejándolos sin protección con relación a su victimización en abusos sexuales, es una absurda manera de hacerlos responsables de su desgracia e incapaces de defenderse. Puede haber ausencia de elementos demostrativos del delito, ya sea porque no suelen producirse en muchos de ellos huellas identificables en los exámenes médicos legales y criminalísticos, o porque el delincuente los ejecuta en ausencia de testigos que harán materialmente imposible su probanza en nuestro medio. Conocedor de todo esto, el acusado dará un testimonio que se caracterizará, en la mayoría de los casos, por la negación confiada de los hechos que se le imputan e incluso por exacerbar rasgos de la conducta de niño o de la familia en su cuidado y educación.

La mayor parte de los infantes víctimas provienen de hogares disfuncionales, promiscuos, deformantes. Restar credibilidad al testimonio del niño(a) argumentando que su medio es anormal, inductor, interesado en el lucro, resulta contradictorio. Comparar la buena trayectoria social, impecable incluso, como aval a favor del acusado, opuesta a la procedencia de un medio más rechazable de la víctima, cuando en el proceso de cálculo del autor tal gradiente pudo ser decisivo para que pasara el acto delictivo, por sentirse poseedor de una fiabilidad social más ventajosa, resultaría absurdo.

Razonar que porque un niño(a) sea mentiroso habitualmente, miente también al razonar sobre el hecho delictivo que fue objeto, pudiera calificarse de absurdo, cuando se razona que precisamente es más seleccionable que cualquier otro para ser victimizado, por esa misma razón garantizadora de impunidad y también reflejo de 
condiciones psicosociales favorecedoras de la victimización.

Todos estos niños se examinan mediante un control semántico discutido en equipo para llegar a conclusiones uniformes en cuanto a validación de testimonio y conducta a seguir, obteniendo como resultado la clasificación del testimonio en tres tipos: a) testimonio confiable cuando las declaraciones del menor no presentan contradicciones, la narración es coherente y con el estado afectivo que corresponde a este hecho, coincidieron la víctima y el victimario en el lugar y el tiempo en que se desencadenan los hechos, tiene valor judicial; b) testimonio dudoso si han existido contradicciones en las declaraciones que no permiten pensar con nitidez los hechos acaecidos, presenta contradicciones esenciales en el fondo del testimonio el cual es real, pero presenta determinados adornos que denotan influencien el niño y c) testimonio no confiable ya que los elementos que se manifiestan en las declaraciones y los hechos no se corresponden con la posibilidad real de hubiesen ocurrido en el tiempo y espacio que se describe, no significa que no ocurrió el hecho sino que su testimonio no puede ser o no tiene valor judicial.

La Instrucción No. 173, del 7 de mayo de 2003, se pronuncia por la participación del menor víctima en el juicio solo si es imprescindible, atendiendo al, "interés superior del niño".

La revisión de los estudios empíricos actualizados con relación a la temática de las capacidades testificales infantiles permite concluir que es posible obtener testimonios por parte de los niños(as) que sean concordantes con los hechos vivenciados (Instrucción No. 173/03). Los niños presentan mayores capacidades para testificar de lo que el sentido común podría suponer hasta ahora y que más bien, el supuesto general se basa en prejuicios poco fundamentados empíricamente. Esto puede resultar riesgoso, si los agentes administradores de justicia se basan en prejuicios más que en evidencias al valorar la credibilidad del relato del niño(a). Por ello no debe resultarnos suficiente aplicar y transmitir una adecuada técnica jurídica, 
se requiere lograr convicción para transmitir certeza.

\section{CONCLUSIONES}

Los infantes sufren el hecho de ser cuestionados al describir el hecho en el que fueron víctimas de delitos sexuales y en un significativo número de oportunidades su testimonio es el medio de prueba fundamental con el que contamos para demostrar su existencia.

La protección de los derechos de los(as) niño(a)s durante la investigación de delitos sexuales, requieren un elevado nivel de profesionalidad de los fiscales para lograr efectividad en el ejercicio de la acción penal y aún subsisten deficiencias que demandan de una constante preparación y perfeccionamiento de los procedimientos.

\section{A CONVICÇÃO, UMA ARMA IMPRESCINDÍVEL NA PROTEÇÃO DE MENINAS E MENINAS VÍTIMAS}

\section{RESUMO}

Neste artigo se valora a convicção como imprescindivel ao tratamento às vitimas específicas de meninos e meninas, observando como isto é tratado no Derecho Penal. Resalta para la Fiscalía, também para Cuba como um país que tiene como prioritário este ponto. Valora a defensa aos infantes vítimas como uma tarefa de todos, ademais deve se ter como prioridade. Aborda o conceito de vítima como qualquer pessoa que tenha sofrido dano físico, psíquico, financeiro ou de seus direitos como pessoa a consequência de una ação ou omissão regida na Lei como delito.

Palavras-chave: Convicção. Vítimas. Proteção dos meninos e meninas. 


\section{REFERENCIAS}

CUBA. Constitución de la República de Cuba. 1992. Editora Política, La Habana.

BARRIOS, Crespo; IVIS, Ana; CANTOS, Iván Cruz Álvarez. 1999. Maltrato en la Adolescencia. Manual de prácticas clínicas para la atención integral a la salud del adolescente. MINSAP, La Habana, Cuba.

Diccionario ilustrado de la lengua española ARISTOS. 1985. Editorial científico técnica.

CHILE. Evaluación Pericial Psicológica de Credibilidad de Testimonio. 2008. Documento de Trabajo interinstitucional. Santiago de Chile.

GÓMEZ PÉREZ, Ángela. Ponencia "Aspectos puntuales acerca de la victimología". Departamento Ciencias Penales.

Instrucción No. 173/03, del Consejo de Gobierno del Tribunal Supremo Popular.

Instrumentos Jurídicos Para la Infancia. 1996. Convención Internacional de los Derechos del Niño. Editorial La Primera Prueba C. A UNICEF, Venezuela. CUBA. Ley No. 1289, Código de Familia. 1989. Universidad de La Habana. CUBA. Ley No. 59, Código Civil. 1998. Ministerio de Justicia, La Habana. CUBA. Ley No. 87, Código Penal anotado y concordado con Instrucciones y sentencias del Tribunal Supremo Popular. 1998. Editorial de Ciencias Sociales, La Habana.

Presentación a la Comisión Interamericana de Derechos Humanos sobre la Situación General de la Niñez en México y Centroamérica. Por Bruce Harris. Director Regional para América Latina de Casa Alianza. 11 de octubre del 2000. Tomado de Internet.

RODRÍGUEZ MANZANERA, Luis. Victimología y Derechos Humanos. Editorial del Puerto, Buenos Aires, Argentina. 1996.

ROQUE, Juan Carlos. 20-6-2001. Nuevos enfoques en la formación de los niños. A iniciativas de 18 premios novel de la paz, la ONU ha presentado en Viena, Austria, la "Década internacional para una cultura de paz y renuncia a la violencia para los niños del mundo". Radio Nederland. Tomado de Internet. 